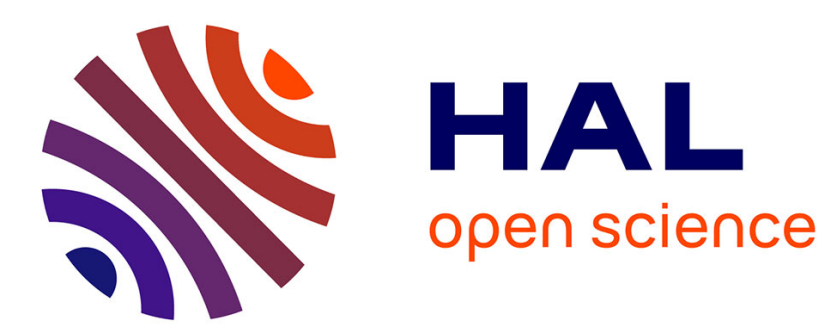

\title{
Book Review: Space Weather, Environment and Societies
}

Robert M. Robinson

\section{To cite this version:}

Robert M. Robinson. Book Review: Space Weather, Environment and Societies. Space Weather: The International Journal of Research and Applications, 2006, 4, pp.S05004. 10.1029/2006SW000243 . insu-00357971

\section{HAL Id: insu-00357971 https://hal-insu.archives-ouvertes.fr/insu-00357971}

Submitted on 3 May 2021

HAL is a multi-disciplinary open access archive for the deposit and dissemination of scientific research documents, whether they are published or not. The documents may come from teaching and research institutions in France or abroad, or from public or private research centers.
L'archive ouverte pluridisciplinaire HAL, est destinée au dépôt et à la diffusion de documents scientifiques de niveau recherche, publiés ou non, émanant des établissements d'enseignement et de recherche français ou étrangers, des laboratoires publics ou privés. 


\title{
Book Review: Space Weather, Environment and Societies
}

\author{
Robert M. Robinson \\ Published 5 May 2006.
}

Citation: Robinson, R. M. (2006), Book Review: Space Weather, Environment and Societies, Space Weather, 4, S05004, doi:10.1029/2006SW000243.

Space Weather, Environment and Societies

By Jean Lilensten and Jean Bornarel

XIII; Springer; 242 pp.; Hardcover; ISBN: 1-4020-4331-7; 2006; $\$ 129.00$

Space Weather, Environment and Societies, by J. Lilensten and J. Bornarel, attempts to bring space weather into the limelight as a new science and as a phenomenon with increasingly serious impacts on civilization. The main part of the book consists of two chapters that describe the physics of the Sun and of the Earth, followed by a third and concluding chapter that contains a summary of space weather effects on technical systems. As admirable as the goal of this book is, it never quite strikes a consistent chord in terms of content, organization, accuracy, or readability. Originally in French, and translated into English presumably by the authors and several cited English translation readers, the book nonetheless contains many English usage errors, which further mar its message.

The main difficulty with the book is its attempt to include something for everyone. To accomplish this, information is distributed among the main text, the footnotes, and the appendices so that readers may selectively read only those portions appropriate to their scientific and technical backgrounds. However, there is little consistency in the level of complexity within the three formats that would allow readers to take advantage of this approach. For example, one footnote provides the expressions for the angle and length of field lines in an Archimedean spiral, while another describes how to construct a pinhole camera to observe a solar eclipse. The introduction claims that "a well informed or hurried reader can read [the book] in one sitting." This may be true if one ignores the footnotes, but the inconsistency in the content of the footnotes may make readers wary of missing something important contained in the fine print at the bottom of the page.

Ultimately, the distribution of text among the main body of the book, footnotes, and appendices becomes a distraction to readers of any level. The lack of consistency in sub- ject matter conveys the suspicion that the authors themselves were not sure at what level to write the book. This impression emerges at the outset, as the introduction contains little or no information about the objectives of the book or the targeted audience. Even a coherent, concise definition of space weather is missing from the introduction. Additionally distracting is that the text is permeated with numerical facts that make casual reading cumbersome and are probably superfluous to readers more interested in learning about the physical processes at work.

In the chapter on the Sun, the text is accompanied by dramatic and colorful figures (mostly from the SOHO satellite) that effectively portray the Sun as an extremely complex system that is still not well understood. The discussion is thorough, and attempts are made wherever possible to use analogies to explain complex concepts, like a pot of boiling water to illustrate convection in the Sun. This chapter is successful in that readers will come away with a greater respect for the Sun's latent power, only a small fraction of which is required to produce dramatic space weather effects on Earth. The final section of the chapter describes the Sun as the source of space weather. Where this section could have set the stage for the remainder of the book, it is instead a summary that repeats much of the numerical data presented in earlier sections.

The chapter on the Earth begins with information about other planets in the solar system and Earth's internal structure. These topics are probably included for completeness even though neither is really relevant to a discussion of space weather. On the other hand, despite a thorough explanation of the Earth and its atmospheric layers, no discussion of waves and tides in the atmosphere is included. The description of the magnetosphere and ionosphere contains neither an explanation of convection at high latitudes, nor one on how ionospheric electrical conduction determines current flow in the upper atmosphere. The final section of the chapter contains a description of high-altitude lightning flashes (sprites and blue jets) that is extremely superficial. Because this section follows a description of aurora, naïve readers may conclude 
that sprites and jets are high-latitude phenomena, particularly because there is nothing in the two-page discussion that connects these phenomena to thunderstorms.

What could have distinguished this book from others aimed at describing the solar-terrestrial environment is the chapter dealing with space weather effects on "environments and societies." Unfortunately, the authors provide only a cursory examination of the technical impacts of space weather. This superficiality could have been offset by comprehensiveness, except that the important topic of scintillations is not mentioned at all. Most of the illustrations in this chapter are of satellites that have little to do with space weather impacts, for example, a picture of an Ariane 5 launch, an image of the European Remote Sensing Satellite (ERS-1) as obtained by the SPOT-4 satellite (Satellite Pour l'Observation de la Terre), and a wide-angle photograph of the Russian space station Mir.

The most unnecessary shortcoming of this book is the many mistakes in the translation from French to English, which easily could have been corrected through a thorough examination by any English-speaking scientist. The book would have been more readable had it been thoroughly checked for such errors. Examples include "impacts" instead of "collisions", "principal sequence" instead of "main sequence," "heart" instead of "core" (as in the Sun's core), "revision" instead of "derivation," "half-big" instead of "semimajor," "medium latitude" instead of "mid-latitude," and "spatial environment" instead of "space environment." We also read about data plotted "according to the years" instead of "as a function of year," the LASCO/SOHO instrument being "dazzled" by sunlight, "more brutal collisions" (of particles), and "sumptuous polar lights" occurring at high latitudes. The authors also refer to "solar aggressions" and "the Sun's anger," which may have been done intentionally, but this terminology gives the Sun a human aspect that is out of context in this type of book.

These might be considered minor annoyances to be expected and forgiven in a translated book, but in some instances the consequences are more serious, as readers may not always be able to distinguish between a real error and an error in translation. For example, aeronomy is defined as "a branch of geophysics that describes the phenomena covered in the previous chapter" (i.e., The Earth). Then on page 126, space weather is described as "not merely an offshoot of aeronomy but a new branch of astrophysics," contradicting the claim on the back cover of the book that space weather is "a developing field within astronomy." Astronomy and astrophysics focus on the study of stars and galaxies, while aeronomy is the study of the physics and chemistry of Earth's upper atmosphere. Space weather can in no way be thought of as an offshoot of any of these disciplines. It is more accurate to say that space weather is a specialized field of space physics that focuses on the Sun and Earth as a coupled system, and how this system affects human technology. The authors' failure to grasp the real meaning of space weather probably accounts for the enigmatic title of chapter 3: "Toward a Space Weather."

The book contains other mistakes on several levels, ranging from misspelled words and inconsistencies in punctuation to factual errors. Some may be too subtle to be noticed by most readers but are inexcusable nonetheless. For example, the authors assert that the distinction between a magnetic substorm and a magnetic storm is that a storm is a substorm that extends to low latitudes. In one section, the auroral oval is identified with precipitation from the outer radiation belts, while in a subsequent section it is (correctly) related to the plasma sheet.

The book concludes with 23 appendices containing detailed information on the derivation of expressions for such quantities as the dipole magnetic field, the Coriolis force, Kepler's laws, and the motion of a charged particle in a magnetic field. Surprisingly, these appendices can serve as a useful reference tool for space scientists because they include derivations related to space weather that one would ordinarily have to search for in several different types of textbooks. The level of detail in these derivations is not sufficient to use in a teaching context, but for a quick reminder of the assumptions and mathematical steps used in the analyses, the depth of explanation is quite adequate.

Perhaps the most positive aspect of the book is the writing style, which somehow emerges in spite of the editorial errors and mistranslations. The authors appear genuinely excited about space weather as a new discipline, and the beauty and excitement of the physical phenomena at the heart of space weather. The chapter on space weather effects conveys the message that the space environment can produce unexpected and dramatic impacts on a broad range of technical systems. The authors' approach also emphasizes the importance of studying space weather as a connected system, where "each layer interacts with the others...."

Books on space weather are only beginning to appear in bookstores. It would be gratifying to say that this book is a valuable contribution to the existing collection of publications on this topic, but unfortunately Space Weather, Environment and Societies misses the mark in terms of both content and readability.

Robert M. Robinson is a program director in the Division of Atmospheric Sciences of the National Science Foundation, located in Arlington, $\mathrm{Va}$. 